\title{
Médiévales
}

Langues, Textes, Histoire

65 | automne 2013

Le couple dans le monde franc

\section{Warren T. WOODFIN, The Embodied Icon. Liturgical Vestments and Sacramental Power in Byzantium} Oxford, Oxford University Press (Oxford Studies in Byzantium, XXXV), 2012, 339 p.

\section{Benjamin Moulet}

\section{(2) OpenEdition}

\section{Journals}

Édition électronique

URL : https://journals.openedition.org/medievales/7142

DOI : $10.4000 /$ medievales. 7142

ISSN : 1777-5892

Éditeur

Presses universitaires de Vincennes

\section{Édition imprimée}

Date de publication : 1 décembre 2013

Pagination : 191-192

ISBN : 978-2-84292-396-9

ISSN : 0751-2708

Référence électronique

Benjamin Moulet, «Warren T. woodfin, The Embodied Icon. Liturgical Vestments and Sacramental Power in Byzantium », Médiévales [En ligne], 65 | automne 2013, mis en ligne le 20 janvier 2014, consulté le 22 avril 2022. URL : http://journals.openedition.org/medievales/7142 ; DOI : https://doi.org/10.4000/ medievales.7142

Ce document a été généré automatiquement le 22 avril 2022.

Tous droits réservés 


\section{Warren T. WOODFIN, The Embodied} Icon. Liturgical Vestments and Sacramental Power in Byzantium

Oxford, Oxford University Press (Oxford Studies in Byzantium, XXXV), $2012,339 \mathrm{p}$.

\section{Benjamin Moulet}

\section{RÉFÉRENCE}

Oxford, Oxford University Press (Oxford Studies in Byzantium, XXXV), 2012, 339 p.

1 Dans cet ouvrage, l'auteur s'intéresse au corpus, assez mince du reste, des vêtements liturgiques brodés byzantins encore existants et qui datent pour l'essentiel de la période allant de la fin $d u X^{e}{ }^{e}$ siècle au milieu du xve siècle, c'est-à-dire à partir du moment où la broderie liturgique prend tout son essor. En confrontant ces données aux rares sources textuelles qui en font mention, l'auteur cherche à reconstruire une histoire de ces vêtements, mais surtout à comprendre le contexte dans lequel ils ont été conçus - contexte qui est, selon ses termes, multidimensionnel, puisqu'il est à la fois spatial (celui de l'église dans lequel le prêtre célèbre les rites dans ses vêtements liturgiques), visuel (images fixes aux murs des églises et images mobiles que constituent ces vêtements) et politico-culturel, puisque l'auteur étudie également les liens étroits entre la tradition vestimentaire liturgique et celle en vigueur à la cour impériale de Constantinople. On trouvera en annexe à l'ouvrage, en plus de nombreuses illustrations en noir et blanc, mais aussi en couleurs, la liste des vêtements brodés connus, la mention de ces pièces dans les textes et enfin les prières relatives à ces vêtements (p. 214-290).

2 L'idée-force de cet ouvrage est de montrer que l'histoire du vêtement liturgique brodé constitue un moyen de comprendre les évolutions des derniers siècles de l'Empire, quand celui-ci est soumis aux attaques extérieures et aux conquêtes (des Latins 
d'abord, des Turcs ensuite). L'auteur fait le constat que l'essor de la broderie est contemporain de la diminution de la production des soieries de grande qualité pour lesquelles l'Empire - Constantinople en tête - était réputé; selon lui, les moyens de production étaient plus flexibles pour la broderie que pour la soie, et ce même s'il était nécessaire d'importer de nombreux matériaux.

3 L'ouvrage est construit en deux parties. La première, intitulée « Liturgical Vestments in the Orthodox Church», compte trois chapitres. Dans le premier («The Vestments of the Byzantine Rite Described », p. 3-46), l'auteur présente les formes et les fonctions des vêtements utilisés dans la liturgie byzantine, qui constituent des marqueurs pour refléter le rang de ceux qui les portent au sein de la hiérarchie ecclésiastique. Le deuxième chapitre ( Moving Pictures : Embroidered Vestments and the Iconography of the Church Interior», p.47-102) étudie l'imagerie utilisée sur ces vêtements, en montrant le lien très fort qui existe entre ces images et celles qui sont peintes dans les églises, permettant ainsi aux fidèles de donner du sens à la liturgie. Dans le troisième chapitre («Liturgical Mystagogy and the Embroidered Image », p. 103-129), l'auteur fait appel aux sources textuelles, et notamment aux commentaires liturgiques, pour montrer que ces vêtements sont le double visuel des prières et actions liturgiques, et il établit le parallèle, déjà évoqué, entre images fixes (celles de l'église et celles, symboliques, de la liturgie) et images mobiles (sur les vêtements des clercs).

4 La deuxième partie ( Liturgical Vestments in Byzantine Society») élargit le propos. Dans le chapitre quatre ("Earthly Rivalry: Imperial and Ecclesiastical Dress», p. 133-177), l'auteur établit un parallèle entre les costumes utilisés à la cour impériale et ceux utilisés dans l'Église, dans les deux cas selon une hiérarchie très stricte et typiquement byzantine. Dans le dernier chapitre ( $"$ As it is in Heaven : Vesture and the Unseen World», p.178-207), c'est l'imagerie byzantine du monde céleste qui est sollicitée. La cour impériale constitue dans l'idéologie byzantine l'exact reflet de la cour céleste, et les vêtements liturgiques se sont joints à cette imagerie. Si l'empereur apparaît comme le représentant de Dieu sur Terre, les vêtements des clercs sont ceux du Christ et des anges : dès lors, la hiérarchie ecclésiastique est assimilée à celle du ciel, signe pour l'auteur d'un changement majeur dans la position idéologique de l'Église byzantine, qui affirme ainsi son pouvoir et sa place à une époque où l'on considère généralement - et pas forcément à juste titre d'ailleurs - le pouvoir impérial comme faible et sur le déclin; l'auteur fait d'ailleurs remonter ces changements à la fin du $\mathrm{XI}^{\mathrm{e}}$ siècle, soit déjà à l'époque, plus prospère, des Comnènes.

Alors même que l'Église entretient volontairement l'idée qu'elle est immuable, dans ses idées comme dans ses traditions, l'étude de $\mathrm{W}$. T. Woodfin montre bien qu'il n'en est rien : en adoptant pour ses vêtements liturgiques brodés l'imagerie des habits de cour, l'Église a évolué dans ses conceptions pour affirmer et renforcer le rôle sacramentel et hiérarchique de ses membres. Ainsi, la décoration des vêtements permet aux clercs et aux fidèles d'être pleinement intégrés à la liturgie comme aux évolutions idéologiques de l'Église, tout en donnant un sens précis aux mystères des célébrations religieuses, en particulier de l'eucharistie. Cela permettait aussi au peuple d'avoir, selon les mots de l'auteur, un accès immédiat à la compagnie du ciel par l'intermédiaire du clergé, qui se considérait lui-même comme la continuation de la hiérarchie céleste. 